\title{
The Chase-Maxwell ratio
}

\section{Pliny Earle Chase LL.D.}

To cite this article: Pliny Earle Chase LL.D. (1885) The Chase-Maxwell ratio, Philosophical Magazine Series 5, 19:121, 519-520, DOI: 10.1080/14786448508627714

To link to this article: http://dx.doi.org/10.1080/14786448508627714

$$
\text { 册 Published online: } 29 \text { Apr } 2009 .
$$

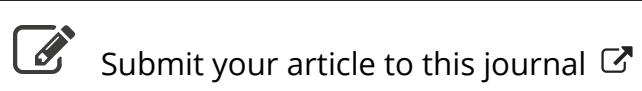

\footnotetext{
Џll Article views: 2
}

Q View related articles $\sqsubset$ 
force (at Sun's surface) would be $k^{4}$ times as great, or

$$
\frac{\mu \pi^{2} k^{4} v_{k}^{2}}{2}=\frac{\mu v_{0}^{2}}{2}
$$

$k$ being the ratio of the Kantian radius to the solar radius.

The time which would be required to communicate this maximum energy is $t_{k}$, the time of virtual projection against uniform resistance, in the region of greatest solar energy, which is also the time of solar half-rotation, as well as the minimum time of synchronous elliptic, circular, and radial oscillation in the solar system.

The ordinary thermal and gravitating units may be deduced from the general unit by means of the equations

$$
\begin{aligned}
& g_{n}=\frac{m_{n} r_{0}^{2} v_{0}}{m_{0} r_{n}^{2} t_{k}} \\
& \mathrm{~T}=\frac{v_{0}^{2}}{2 g_{3}{ }^{2}} .
\end{aligned}
$$

In the second of these equations $\mathrm{T}$ represents the mass of water which could be heated one degree by $\mu$ of oscillating luminiferous æther, or the number of degrees to which $\mu$ of water could be heated ; $g_{3}$, gravitating acceleration at Earth's equator ; $h$, the linear dimension of the mechanical unit of heat.

The barmonic values are as follows :-

$$
\begin{aligned}
m_{0} & =329414 m_{3}, \\
r_{0} & =198 \cdot 923 r_{3}, \\
g_{0} & =27 \cdot 765 g_{3}, \\
v_{0} & =185500 \text { miles per second, } \\
g_{3} & =32 \cdot 033 \text { feet per second, } \\
\mathrm{T} & =10,775,492,000,000^{\circ} \text { C. - Communicated by the Author, }
\end{aligned}
$$
having been read before the American Philosophical Society, April 17, 1885 .

The CHASE-MAXWELL RATIO. BY PLINY EARLE CHASE, LL.D.

In 1872 (Proc. Amer. Phil. Soc. xii. p. 394) Chase showed that the tendency of particles, in exploded gases, toward primary and secondary centres of oscillation leads to a permanent vis viva of equilibrium which is $\frac{5}{9}$ of the vis viva of explosive projection, and that the synchronous action of the Sun and the Earth upon the oscillating particles furnishes a ready method for estimating the Sun's mass and distance. He also showed (ibid. pp. 403-405) that the successive planetary positions in the solar system illustrate the influence of æthereal oscillations of a similar character. In 1875 he showed (op. cit. xiv. p. 651) that the mean velocity of expanding gaseous pressure is $\frac{2}{\pi}$ of the corresponding constant velocity of rerolution; the ratio of vis viva 
is therefore $\frac{4}{\pi^{2}}=\cdot 405285$, and we have

$\mathrm{K}: k:: 1 \cdot 405285: 1$.

In 1877, Preston (Phil. Mag. iii. p. 453; iv. p. 209) showed "that a physical relation exists between the velocity of the particles of a medium constituted according to the kinetic theory, and the velocity of propagation of a wave in the medium." Maxwell calculated the numerical value of this relation at $\sqrt{\frac{5}{5}}$, which represents Chase's ratio of relative vis viva; but he did not give the method by which he reached that result, and no record of it was found among his papers. The following thermodynamic demonstration may therefore be satisfactory to those who have found any difficulty in accepting the more simple and more general photodynamic proof which is furnished by reference to oscillatory centres.

If we represent the density of a gas, $\frac{n m}{v}$, by $\rho$, the fundamental equation of pressure becomes

$$
p_{\mu}=\frac{\rho c^{2}}{3}=\frac{p_{0}}{3}
$$

Alexander Naumann (Ann. Pharm. 1867, pp. 142, 267 ; J. B. 1867, p. 62) showed that

$$
\mu=\frac{3}{2}\left(\gamma^{\prime}-\gamma\right), \ldots \ldots \ldots \ldots \ldots \ldots \ldots
$$

$\mu$ being the heat of molecular motion, or mean vis viva of a perfect gas ; $\gamma^{\prime}$, the specific heat under constant pressure; $\gamma$, the specific heat under constant volume; $\gamma^{\prime}-\gamma$, the heat of expansion, or vis viva of mean velocity. The total specific heat is therefore

$$
\theta=\mu+\gamma^{\prime}-\gamma=\frac{5}{3} \mu . \ldots \ldots \ldots \ldots \ldots \ldots
$$

Hence

$$
\begin{aligned}
& p_{\theta}: p_{0}:: 5: 9 \\
& v_{\theta}: v_{0}:: \sqrt{5}: 3 .
\end{aligned}
$$

Prof. d'Auria, in a special investigation relating to the dynamics of direct-acting pumping-engines, not yet published, has found, by analogy, that

$$
\mu=\frac{6 \gamma}{\pi^{2}}=607927 \gamma \ldots \ldots \ldots \ldots \ldots
$$

Substituting this value in eq. (2) we get Chase's result :-

$$
\begin{aligned}
\gamma^{\prime}-\gamma & =\cdot 405285 \gamma \ldots \ldots \ldots \ldots \ldots \ldots \\
\gamma^{\prime} & =1 \cdot 405285 \gamma, \ldots \ldots \ldots \ldots \ldots
\end{aligned}
$$

The exactness of agreement between this $\dot{a}$ priori value and the one which was found by Röntgen (1.4053 ; Pogg. Ann. 1873, pp. 148, 603) is very remarkable.-Communicated by the Author, having been read before the American Philosophical Society, April 17, 1885. 